\title{
The mobile learning conscious tutor: Incorporating Facebook in tutorials
}

\section{Diana Nadine Robertson}

Department of Education and Curriculum Studies, University of Johannesburg, Johannesburg, South Africa 920402475@student.uj.ac.za

https://orchid.org/0000-0001-8746-2125

\section{Nazreen Dasoo}

Department of Education and Curriculum Studies, University of Johannesburg, Johannesburg, South Africa ndasoo@uj.ac.za

https://orcid.org/0000-0002-8671-4340

(Received: 17 February 2019; accepted: 8 September 2019)

\section{Abstract}

Today's students are digital natives, and advances in mobile technology should impel institutions of learning to revaluate their tutoring systems. Our study explored tutors' potential to introduce mobile learning through the social media application, Facebook, in tutorials conducted at the University of Johannesburg's faculty of education. This study further considered the tutors' potential to motivate students to use their devices for learning on social media through professional communities of practice online. Our exploratory qualitative study sought to understand the perception of tutors and tutees about the inclusion of Facebook through in-depth reviews of the literature, focus group interviews, questionnaires, and online log data responses. The data was thematically analysed and the results suggest that tutors can encourage students to use their devices for academic purposes through online Facebook discussions. Our conclusion is that the inclusion of Facebook as part of the tutorial experience can support virtual professional communities of learning online beyond the traditional physical and formal tutorial.

Keywords: mobile devices, tutorials, tutoring, tutors, virtual communities of practice

\section{Introduction}

We are living in exciting times for society in general and academia in particular, as higher education institutions (HEIs) acquire a unique opportunity to shift from traditional teaching and learning perspectives, to positioning themselves at the forefront of adopting, if not designing, technologies for the renewal of teaching and learning. South Africa has welcomed mobile learning and, as a result, we have proven to be capable of introducing our own 
contextually significant tools (Ivala \& Gachago, 2012; Ng'ambi et al., 2015; Veletsianos, 2010). In spite of the inclusion of mobile learning approaches in HEIs, little research has been done on tutors who incorporate technology and social media for teaching and learning in the tutoring process. Current studies on tutoring are primarily centred on evaluating tutorials and enhancing learning to improve the academic performance of tutees (Coughlan \& Stephen 2011; Hassan, 2017; Shaw, Carey, \& Mair, 2008). Other studies focus on the transferring of discipline-specific skills (Underhill \& McDonald, 2010), and determining the effectiveness of tutoring in the enhancement of learning (Truuvert, 2014).

However, there is need to focus on "communication networks through the Internet to improve pedagogy” (Ng'ambi, Brown, Bozalek, Gachago, \& Wood, 2016. Several South African researchers promoting authentic learning have embarked on documenting the use of Facebook in learning practices such as microbiology, engineering (Ivala \& Gachago, 2012; Ng'ambi et al., 2015), and education (Robertson \& Dasoo, 2018, p. 65). Facebook is widely used to bridge the communication divide (Gachago, Ivala, Backhouse, Bosman, \& Bozalek, 2013). It is a social networking tool that has created an "increase in pedagogical investigations . . . for educational purposes" (Ng'ambi et al., 2015, p. 10), and it can create virtual communities of practice across institutions with as online learning spaces to provide opportunities for group problem-solving and peer-to-peer collaboration (Council of Higher Education, 2014). Facebook is a social network application that can be used as a discussion forum for collaboration in communities of practice supported and implemented by tutors.

The purpose of this paper is to fill a knowledge gap in the tutoring literature that seeks to understand the environment of tutorials and how tutors manage and effectively tutor using technology. The two research questions considered to fulfil this purpose were: "How do tutors use Facebook to enhance the way in which they tutor?" and "How do tutees experience the implementation of Facebook during tutorials?"

\section{The rationale of the investigation}

The context of this study is the University of Johannesburg (UJ), which set out to establish new and effective ways of teaching and learning. The university disseminated eight strategic goals to fulfil its mission by 2020. One of these goals is teaching and learning using $21 \mathrm{st}$ century technology, and the university stakes its "reputation as a comprehensive institution with a unique identity in the higher education sector [on] the stature and quality of its scientific and technology-rich programs and its scientific and technology-driven research, innovation, and technology transfer" (University of Johannesburg, 2011, p. 5). Accordingly, the university embarked on the infrastructural changes required to accommodate mobile learning access over its four campuses. According to Louw (2015, p. 294), UJ boasts to be "one of the largest wide area networks in the southern hemisphere that is Wi-Fi compliant with various hotspots on its campuses." The university is thus prepared for the inclusion of technological advancements in education but teaching staff (including tutors) are not fully engaging technology within teaching and learning (Louw, 2015). According to Brooks (2008) and Jaeger (2016), tutoring as instructional method dates back to Socrates and the Socratic 
method. This approach consists of a partnership between the more experienced student (tutor) and the inexperienced student (tutee). It ensures that knowledge and practices are simplified and passed on to the tutee. Tutors have essentially remained the same, which implies that relationship between tutor and tutee has not changed. This study suggests that traditional approaches to tutoring and digital approaches to tutoring constitute an interesting area for inquiry. Accordingly, the study focuses on integrating virtual tutoring with traditional approaches to provide optimal and effective tutoring within and outside the allocated tutorial timeslot.

The inquiry focuses on tutors and the inclusion of technological devices in the one-to-many tutorial setting. Wireless connectivity makes learning through iPhones, tablets, and smartphones possible and enhances students learning experiences anywhere and anytime. This affords functionalities such as Facebook discussion forums for educational occurrences that would otherwise not be possible. It is fair to suggest that technology improves the productivity and efficiency of tutors. It prioritises delivery of information in time and in context for their immediate attention (Kukulska-Hulme, 2010). It is evident that understanding the transformation of tutoring into the digital and technological age within HEIs is crucial for providing an exciting, supporting, and effective tutor-tutee experience.

Although one-on-one instruction has been more effective than one-to-many classroom instruction (Bloom, 1984), it is not economical to provide every student with an individual teacher or tutor (Koedinger \& Corbett, 2006). Tutorials at HEIs are planned and structured to enable tutors to reemphasise concepts within groups and large class settings. Tutorial settings allow for interactive learning; they enable students to clarify and extend discussions and other activities though reading to augment what they learnt from lectures. Active student (tutee) participation ensures that meaningful learning takes place productively in tutorial times. Kukulska-Hulme (2010) indicated that HEIs' workforces are adapting to advancements in technology for teaching and learning. HEIs are identifying exemplars in workplaces to work with the lecturers. These exemplars include tutors whose primary mandate is to support both the lecturers and students (Underhill, 2009).

Tutoring is not without challenges. Tutors are often limited to traditional tutoring styles that are far removed from the students' learning needs. These traditional forms of tutoring are appreciated as a starting point but they are limited in light of changing technology. In as much as institutions are adapting to teaching and learning with technology, so should the tutors. Initial training elements are necessary and have a positive effect on tutors because they provide tutors with foundational support and a reference point (Underhill, 2009). Without proper training, discussions by students tend to revolve around the tutor (Cheung \& Hew, 2009), delayed duties and unavailability of tutors (Klimova \& Poulová, 2015), inadequate skills (Alhassan, Amoah, \& Anyanful, 2018), and insufficient support given (Sundvik, Masalin, \& Hervonen, 2016).

To combat these challenges, a mobile learning approach is considered. As the use of mobile devices has thrived, so has the idea that such devices may be useful in the process of teaching and learning (Khaddage, Muller, \& Flintoff, 2016). This paper considers Facebook 
as a learning tool using mobile devices in the tutorial environment. Although Facebook was created as a social networking website, it later expanded into various educational settings (Hew, 2011). A platform such as Facebook can change the nature of learning because it goes beyond individualistic activity to what Siemens (2005) termed connections and connectiveness through networks that emphasise learning and knowledge from diverse backgrounds.

The advantage of Facebook as a discussion forum is that it allows people to share information, ideas, knowledge, and resources. Espinosa observed that sharing knowledge and information online allows students to

connect the classroom with speakers around the world . . . bring quiet students out of their shell by asking them to participate in Facebook discussions, create study groups to easily connect with each other within their own Facebook groups, track down old students or professionals that could come to the classroom as guest speakers, connect with classes all around the world, and discuss classroom ideas with other teachers on Facebook. All these ideas can contribute to improve students' ... skills. (2015, p. 2207)

Facebook groups facilitate easy, convenient, and quick information dissemination among students. By accessing their group anywhere via Internet-ready electronic devices, students can get notifications and updates on tutorial activity without the need to meet physically with the teacher (Mabuan \& Ebron, 2017). Facebook as a learning environment also has the potential for more student engagement; however, the use of social media should be supported by academics in order to build a community and to increase student engagement at HEIs (Toliver, 2011). Mazman and Usluel (2010) concurred that Facebook as an educational tool encourages active participation and collaboration, and Daraei (2015) argued that Facebook as an educational tool

develops team-working skills; could be helpful for both teachers and students when used as a supportive material in lessons; helps teachers and students to know each other better via the profile pages; could make learning more enjoyable; could increase students' motivation by allowing them to communicate with each other (p. 80).

Learning communities in the virtual space also create space for shy students' voices to be heard. These students can feel empowered enough to raise their opinions on Facebook, something they might be reluctant to do in class (Bosch, 2009).

Other concerns for educators are lack of control and inability to maintain students' attention. If a student is not paying attention, he or she is not learning. Kirschner and Karpinski (2010) concurred that educators want to use technology to expand and strengthen student-learning abilities but have difficulty in maintaining students' attention. The inability to fully realise the educational value of Facebook motivated Manca and Ranieri (2013) to examine the platform as a learning environment. Their study showed that the pedagogical affordances of Facebook have not been exploited enough; concerns with the learning environment, teacher 
and student pedagogies, and cultural issues could hamper the comprehensive acceptance of Facebook as a learning environment for students Manca and Ranieri (2013).

One disadvantage of Facebook and social networking websites is a fear of missing out (FOMO), and is a reality among students - a concern that one might be missing out on rewarding experiences (Przybylski, Murayama, DeHaan, \& Gladwell, 2013)—but tutors and lecturers can leverage FOMO to encourage active and dynamic participation.

There are dangers and challenges that need to be deliberated. For example, social networking involves risks that include privacy being violated, intimidation through bullying, and harmful interactions (Livingston \& Brake, 2010). Cyber bullying becomes a major concern with online applications, and the inclusion of Facebook as discussion forum raises ethical considerations relating to protecting students from abuse in the space. These dangers not only affect students, but to faculty (tutors) too (Minor, Smith, \& Brashen, 2013).

\section{Theoretical Framework}

The notion of communities of practice (CoP) was introduced by Lave and Wenger (1991) who focussed on theories of adult learning. Learning in a CoP takes place "in a certain context where students interact with and learn from peers rather than in a traditional classroom where there is a clear student-lecturer divide" (Wang \& Ma, 2017, p. 19. Participation is an important aspect in a community but the generation of newer or deeper levels of knowledge through the sum of the group activity is even more crucial (Wenger, 2014). Dialogue and collaborative group learning create opportunities for students to work together to solve problems. This strengthens the formed communities of practice. We use $\mathrm{CoP}$ in this study to evaluate tutorial environments using mobile learning.

The concept of virtual communities of practice $(\mathrm{VCoP})$ is rooted in the idea of $\mathrm{CoP}$, and implies that group interaction through an electronic network is similar to CoP. Instead of face-to-face interaction, there is the virtual space. Therefore, VCoP are virtual places of collaboration using tools (Internet platforms) for members to share and create professional knowledge (Dudezert, Heibült, \& Boughzala, 2006)—collaboration through information systems without geographical frontiers. However, if CoPs are small, tight-knit groups consisting of intensive and sustained interactions around a shared practice (Wenger, 1998), then VCoPs should "follow the same pattern, particularly with respect to tie-strength and group size" (Murillo, 2014, p. 2). Internet-based communities can easily number to hundreds of members (Koh, Kim, Butler, \& Bock, 2007). The ties between participants in such large and mostly anonymous collectives can hardly equal the strong relationships that characterise CoPs. Members' contribution to VCoPs is not based on commenting extensively, nor is it a requirement to share sophisticated knowledge or concepts. For a community to be lively and meaningful, members have to participate and activities must stimulate engagement. Online activities can include posting questions for response and comment on discussion boards, engaging in live chats, and video conferencing (face-time discussions; Ardichvili, 2008). Key $\mathrm{CoP}$ characteristics involved in face-to-face and virtual tutorial activities include "a shared 
domain of interest ... engagement in mutual learning and knowledge sharing . . . and shared inventory of resources" (Wang \& Ma, 2017, p. 21).

\section{A shared domain of interest}

VCoPs are not simply tutees and tutors who have similar basic interests. These participants develop a shared selection experiences, stories, tools, and ways of addressing recurring problems. Shared practice that extends beyond the face-to-face tutorial boundaries, and creates possibilities in virtual spaces beyond the venue limitations. A CoP is established on the sharing of past and present views that become rituals in the community (Barab \& Duffy, 2000). In this study, tutees from the Teaching Studies 2 B (TST20B2) module meet regularly for tutorials, and may not realise that their tutorial discussions are one of their main sources of knowledge of the module.

\section{Mutual learning and knowledge sharing}

According to Delahunty, Verenikina, and Jones (2014), participants in online communities have a shared sense of belonging, trust, an expectation of learning, and commitment to participate and to contribute to the community. Learning in online spaces is embedded in Vygotsky's (1978) belief that students working together in a learning context to create new knowledge collaboratively results in social cognition. Members of a VCoP have the potential to support and challenge each other with shared knowledge as well as effective and relevant knowledge construction. Sustained engagement between groups of students (tutees) will eventually create a CoP (Wenger, 1998), involving members' interactions and collaboration to solve problems, develop useful artefacts, and discuss relevant issues. According to Hinds and Lee (2008), mutual engagement makes VCoPs task-oriented, setting them apart from fan clubs or socialisation communities. Through defining the key issues and problems that need to be addressed, the members collectively discuss these and hold each other accountable (Wenger, 1998).

\section{Shared resources inventory}

In the mobile learning focused context, the tutees are able to share information, ideas, and viewpoints online. The use of the Internet and the Facebook discussion forum through mobile devices are useful vehicles to share information (Wang \& Ma, 2017). The notion of "bring your own device" refers to tutees who bring their devices to use actively in the tutorials. In some instances, tutees may use each other's devices collaboratively to work and assist each other.

\section{Experiences of members in a community}

CoPs and VCoPs affect the social aspect of learning as members bring their own life experiences to the learning spaces. The activities that members participate in, and which result in learning within a CoP, is facilitated by members' collective interactions and relationships with others (Lave \& Wenger, 1991). When the tutees share ideas or an interest in the tutorial environment and online, their shared experiences strengthen the community. 
The tutees' and tutors' experiences, how they participate, the challenges, and their perceptions inform this study.

\section{Mediating tools}

Mobile devices enable tutees to learn by exploring their world through communication using technology. Facebook enabled tutees to create VCoPs that support conversations in actual and virtual learning environments. Technology through mobile devices in the lecture venues supports rich conversations between tutees as an extension of learning (Wang \& Ma, 2017). Tools and mediating artefacts include writing, reading, watching, and discussion.

\section{Decision-makers}

Members of the VCoP in this study are the tutees and the tutors. The role players in the tutorial environment are the tutors-divided into senior tutor and tutors. The lecturer is at the top of the hierarchy but has very limited influence in this study given that the focus is on the tutor as leader of tutorials. Leaders have the ability to support practice and set the rules. Tutors in this context are considered the content experts and are therefore able to support the practice and set the rules.

\section{Methodology}

A qualitative methodology was used to collect data for this case study. Mohajan (2018, p. 2) stated that the "qualitative approach is concerned with the individual's opinions, feelings, and experiences to discover unanticipated occurrences." The qualitative approach is suitable because it allowed the researcher to work with perceptions and experiences of tutors about mobile learning at the University of Johannesburg. However, we have used some descriptive statistics in form of numbers and graphs for illustration. Focusing on tutors perceptions and experiences about mobile learning requires a specific approach, hence, a case study was chosen for the investigation. Merriam (2009) said that the use of a case study is suited to examining programmes in order to enhance understanding that may influence practice. In this investigation, the case study consists of the tutees and tutors in the second year of the Teaching Studies (TST202B) module, a bounded context at UJ. This study is also an explanatory case study. Yin (2009) observed that an explanatory case study examines the research issue at a deeper level. This approach emphasises depth analysis of data in order to explain, in this case, tutors' perceptions and experiences of mobile learning.

The data collection instruments used included questionnaires, focus group interviews, and an online discussion forum. The study used purposeful sampling of 423 undergraduate students (tutees) in their second year of education teaching studies. Five tutors and one senior tutor participated in the study. The study used community of practice as its conceptual framework to explain the perceptions of tutors on mobile learning (Hashim \& Jones, 2007). The data from questionnaires, focus group interviews, and an online discussion forum were compiled into an Excel Spreadsheet, and thematic content analysis was used to analyse it (Creswell, 2012). 
An important aspect of research trustworthiness is reliability and validity. Miles and Huberman (1994) referred to reliability as quality control. When considering reliability, the collection of data should be able to be repeated. Validity refers to the accuracy of the findings using certain procedures (Creswell, 2012). Important tactics to consider are the "multiple sources of evidence, establishment of a chain of evidence, and having the draft case study report reviewed by key informants" (Yin, 2009, p. 212). These multiple sources, through triangulation, were considered in order to ensure reliability, validity, and trustworthiness. The combination of questionnaires, focus group interviews, and the analysis of online discussions were checked through triangulation. For example, what was discussed in the focus group interviews could be checked against what was answered in the questionnaires or the online discussion forum responses. For audit trail considerations, we collected data transcriptions, signed consent forms, ethical clearance documents for safe keeping so readers can verify the findings (Schwandt, 2007). We engaged with other academics during the research process to obtain critical feedback and different perspectives on our assumptions.

Ethical considerations included consent obtained from the participants prior to participant interviews, discussions, and questionnaire completion, and after the researchers had explained the aim of the research. Participants were further informed that engaging in the study by sharing their experiences would have no impact on their academic grades and their participation in this research was voluntary and without any form of penalty should they wish to withdraw. The researchers have complied with all the ethical considerations.

\section{Findings and discussions}

The first research question (How do tutors use Facebook to enhance the way in which they tutor?) is discussed below under the following six headings: Facebook as catalyst, tutoring in the 21st century, tutors incorporate mobile devices as a tool, the connected tutor, tutors encourage mobile devices for academic use, and tutor as mediator.

The second research question (How do tutees experience the implementation of Facebook during tutorials?) is discussed thereafter, under the following eight headings: the relevance of Facebook, student-structured learning, working communities, FOMO, cyber bullying, student participation, more student voices, and authentic learning experience. 
Research Question One: How do tutors use Facebook to enhance the way in which they tutor?

Facebook as catalyst

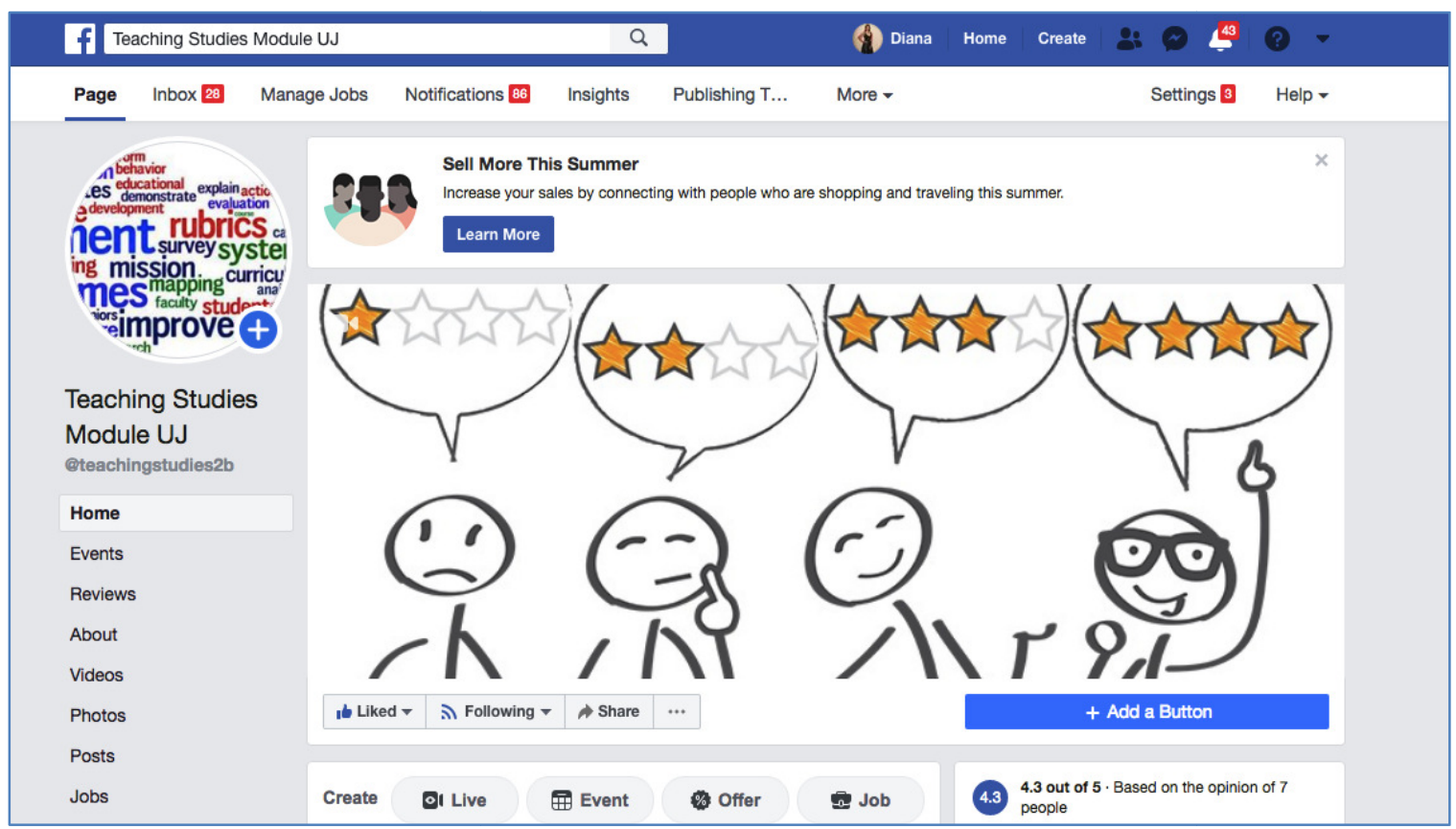

Figure 1: Teaching Studies 2B Facebook cover page

A senior tutor created the Teaching Studies 2 B page on Facebook (see Figure 1) and asked all tutees attending the module to join the group and participate in discussions and activities pertaining to the module. By including Facebook as a means of communication in a large group, the discussions taking place in the tutorials were sparked by the comments and responses from online discussions initiated by the tutors prior to and outside of the tutorial venue. This allowed tutees to attend tutorials prepared and already part of conversations regarding the topics to be covered, and ready to share their perspectives, understanding, and views.

Communication between the tutors and tutees improved. Questionnaire data revealed that, prior to the inclusion of mobile learning, it was evident that communication between tutors and tutees was not effective. Tutors experienced several difficulties because of the tutorial setting. First, tutees did not cooperate and there was poor participation. Second, poor attendance was a concern - the majority of the time, tutees only attended long enough to sign the register. The tutees who did attend were disruptive, some sleeping during tutorials. There was a tacit consensus among tutors that the above was a challenge and a concern, and that was a desperate need to change the situation. Incorporating mobile devices was a relevant solution because tutees already had these tools.

It was a gamble; the uncertainty of the outcome was intimidating because there was no precedence. It would either be very successful and enrich the tutorial experience, or be detrimental with inconceivable consequences. The tutors experienced feelings of doubt when 
considering Facebook. Using it as an online discussion tool meant they had to plan thoroughly and meticulously to adjust their tutoring roles to successfully incorporate the platform. The data revealed that being able to do more and adding a different element to the tutorials (that was relevant to the tutors and to the tutees) created a sense of fulfilment for the tutors. This was a leap from the feelings of despair previously perceived. The majority of the responses were very positive and in favour of the Facebook discussion forum in tutorials.

\section{Tutoring in the 21 st century}

Tutoring has been altered to fit the tutee of the 21 st century. The tutoring structure has changed and, taking into consideration the South African context: language, traditions, and culture, learning should be relevant to tutees at UJ. Standing at the front of a venue, reteaching information, and asking questions does not constitute meaningful engagement. The shift in tutoring through implementation of mobile learning changed attitudes and perspectives; it gave the tutees a different tutoring and learning experience. Responses from the online logs revealed that the 21 st century tutees participating in the tutorials were interested in a new, authentic, and technological way of conducting tutorials.

A need for training with reference to technological advancements was evident. Tutors lacked innovative ways to administer the tutor check-in training sessions and make it more relevant. Before the implementation of the mobile learning, tutors attended tutor preparation training, and it is evident from the transcripts that training for for mobile learning was needed. This is in line with Underhill (2009) who said that one has to establish how one wishes to use tutors and then establish how to train them for that end. Tutors in this study received training to prepare them to tutor in face-to-face tutorials and through the online learning created through the Facebook discussion forum.

\section{Tutors incorporate mobile devices as a tool}

Incorporating mobile devices in tutorials was a new and unique mode of conducting tutorials. A mobile device was seen as a tool to optimise tutorials. The size of mobile devices brought an obvious mobility factor, and participants mentioned the benefit of convenience and portability. The majority of tutees and all the tutors responded that they had a device that would make mobile learning approaches possible; these included handheld computers, mobile telephones, and other devices that draw on the same set of functionalities (Traxler, 2007). The convenience of having a learning tool in one's pocket was supported by tutors. Mobile handheld devices have evolved and, with time, have become smaller, lighter, and convenient to carry, which makes them conducive for learning (Alsaadat, 2009).

\section{The connected tutor}

The data further revealed that the Wi-Fi access allowed for connectivity in lecture venues and hotspot areas around campus. The connectivity supported the portability of mobile devices. The tutors all have compatible devices and $96 \%$ of the tutees were able to access the Internet through their mobile devices. The remaining $4 \%$ were unable to access the Internet on their mobile devices. With access to Wi-Fi granted, tutees were able to participate simultaneously 
and incorporate perspectives from the Internet sources. Tutees without devices or with incompatible devices were able to share devices with peers and participate in group discussions. The tutors were also accessible outside of the lecture venues through the online Facebook page, allowing them to be available and easily reachable. Constant connectivity created an always-connected tutor. The exploitation of ubiquitous handheld hardware, wireless networking, and mobile telephony to facilitate, support, enhance, and extend the reach of teaching and learning within and outside of tutorials was thus possible (MoLeNET, 2010). This allowed tutees to be physically mobile while at the same time remaining connected to non-proximate sources of information, instruction, and data communications technology (Woodill, 2012).

\section{Tutors encourage mobile devices for academic use}

After the mobile learning activities were completed, tutees were asked if these activities encouraged them to use their devices for academic reasons. Eighty-five per cent of the 423 tutees used their devices for academic use, and they appreciated the mobile learning approach incorporated in tutorials. These tutees saw the relevance of using their devices for academics. The remaining $15 \%$ of the students responded, No, to this question. The majority of the tutees were optimistic about using devices in class for academics. For these students, mobile devices improved the productivity and efficiency of tutors by delivering information and support just in time and in context of their immediate priorities (Kukulska-Hulme, 2010. However, the $15 \%$ of tutees remain sceptical. These students felt that using their mobile devices in class hindered their academic performance (Berry \& Westfall, 2015).

\section{Tutor as mediator}

The incorporation of mobile learning through the Facebook discussion platform and tutorial group discussions enabled the tutees to realise and appreciate the clarity of concepts, importance of discussions, and that active participation with activities increased understanding. This allowed tutors to interact on a level that tutees enjoyed and understood. It did, however, effect a change in attitude towards the lectures, and the class attendance dropped. It is important to mention the inclusion of mobile learning in this study had a consequence that lead to a different dilemma. The data revealed that as tutorials became popular and interesting, students chose to attend the tutorials instead of lectures. The technosavvy traits of the tutors exposed the lecturers' limited technological efforts. Often, a tutor is placed in the middle of the digital divide that exists between a student and lecturer in the higher education context. This results in efficient tutoring being hindered.

\section{Research Question Two: How do tutees experience the implementation of Facebook during tutorials?}

\section{The relevance of Facebook}

Initially, communication in the tutorial environment was not conducive to learning. It did not benefit the tutor or the students. Student interaction needed to be encouraged by the tutors to ensure that dialogue, exchanging ideas, and clarifying concepts were dealt with. 
Incorporating a mobile learning approach through a social media application encouraged communication online and initiated face-to-face discussions. In order to start communicating online, it was important to establish which social media application would be most beneficial. Figure 2 indicates that Facebook was the most popular social media platform used amongst tutees.

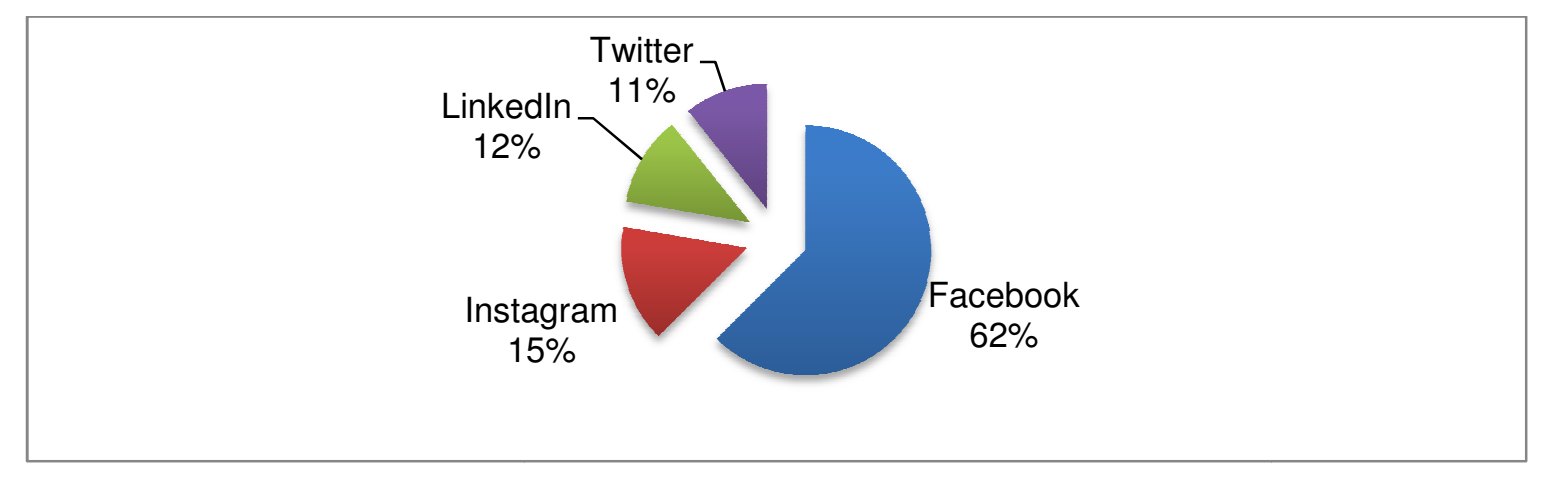

Figure 2: Social media mostly used

Knowing that tutees used Facebook was a positive result for this study, but their perspective on the implementation of Facebook in tutorials was important too.

\section{Student-structured learning}

Student-structured tutorials were non-existent prior to the introduction of mobile learning. Tutoring merely made sure that content was repeated. Incorporating mobile learning turned this negative scenario around. It created space for tutors to think about what students would find useful, and how best they could package it to benefit the tutees for a good learning experience. The introduction of mobile learning ensured that tutees were more involved. The tutees were aware that the new approach to tutorials was primarily about them and was aimed at involving them more in their own studies. The tutors generally felt that the tutorials were now a success and more suited to tutees' needs and how best they would be stimulated to participate effectively. In this sense, it was more tutee structured. If tutors are encouraged, and permitted to incorporate new ways of learning that are student focused, then technological advancements such as mobile learning can constitute part of this innovation and provide a unique learning experience (Traxler, 2010).

\section{Working communities}

The initial data revealed that, prior to the implementation of mobile learning, collaboration was weak. According to the tutees' responses, the blame for poor collaboration was placed on the tutors. The tutees revealed that their poor participation and non-interest in collaboration was due to a lack of support from tutors. However, the data revealed that CoPs became evident after the online element was introduced in tutorials. The tutors formed a community and spent extensive time planning and strategising how they would cultivate and support safe and friendly communities amongst students. In the focus group interviews, CoP was evident as tutors shared their experiences, challenges, and possible solutions (see Figure 3). The workshops, meetings, and training attended by the tutors motivated and empowered them to 
feel safe enough to ask questions and to work together. Another form of CoP manifested in the tutorials among students.

The tutees had similar interests that allow them to form the basis of a community. They all shared an interest in education, teaching, and learning and in the TST20B2 module. The inclusion of mobile learning activities took collaboration to a new level as a VCoP formed. Tutees felt included and they valued the collaborative and social aspects that became an option within group tasks and conversations online. The community that the tutors formed strengthened further and influenced the communities formed among the students. The tutors were an example of what they wanted to see in the tutorials; this allowed and encouraged more students to voice their opinions and understanding. When tutees agree with their tutors, they form social ties, which are important for collaborative learning (Hrastinski, 2008). The forum discussion provides a collaborative learning environment where students learn from each other.

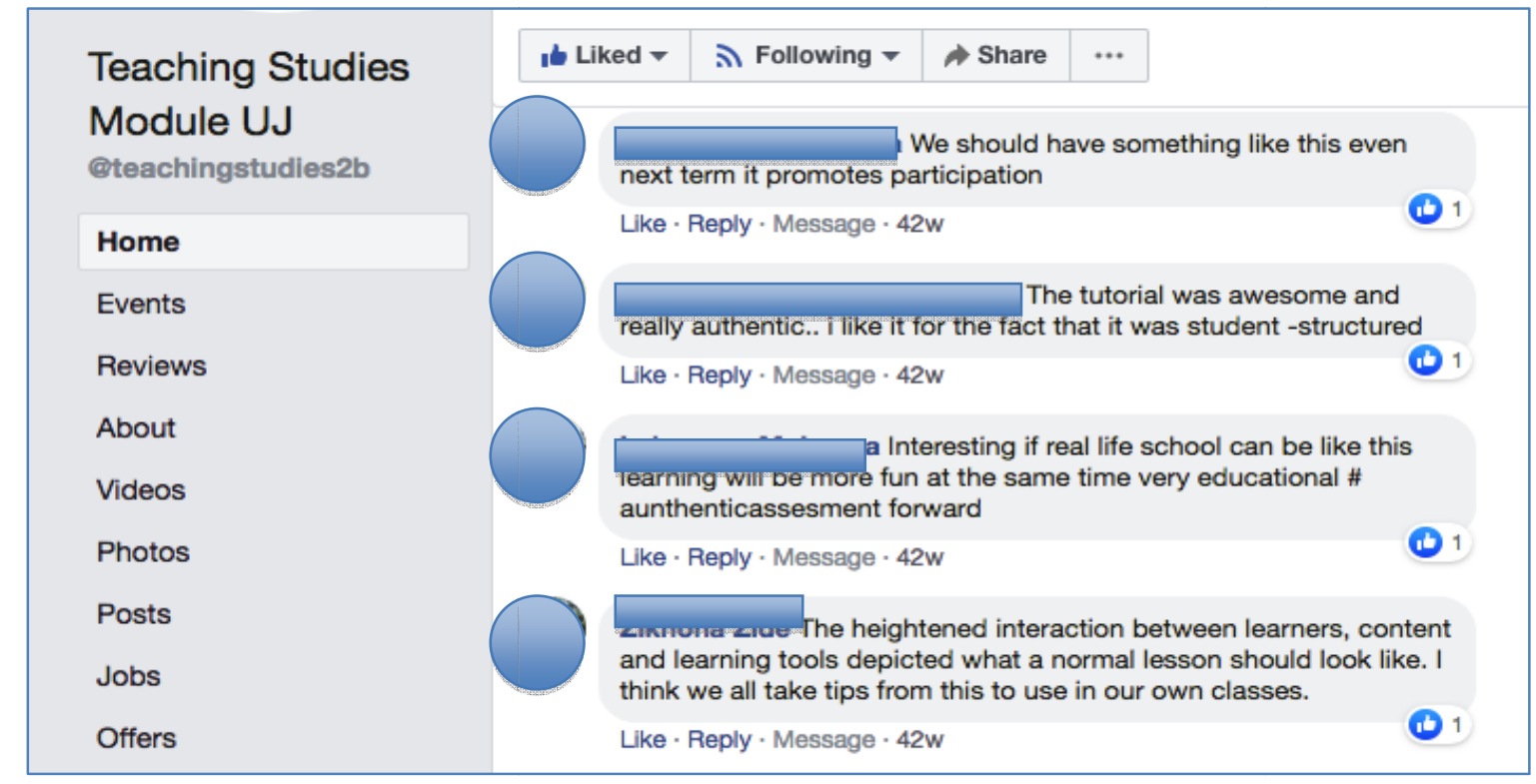

Figure 3: Working communities encouraged (Source: Online Facebook Responses)

\section{FOMO}

For students at HEIs, the fear of missing out is real. The data revealed that there is anxiety of missing out. A contributing factor that leads to the successful incorporation of mobile learning within this study is due to the FOMO factor. The idea of the Facebook page being always on and accessible at any time allowed tutees to participate in discussions before, during, and even after a tutorial was conducted. Therefore, including a Facebook online discussion forum was not only helpful and relevant; it was feeding tutees' desire to know. By introducing mobile learning, tutors leveraged FOMO to inspire and push tutees to actively participate. Quick responses from tutors played into the happening-now content culture of their world. Incorporating Facebook as an educational tool developed team-working skills became a useful educational tool for tutors, made learning in the tutorials 
more enjoyable, and "it increased students' motivation by allowing them to communicate more effectively" (Daraei, 2015, p. 77).

\section{Cyber bullying}

It emerged from the data that tutees were aware of safety considerations in online spaces. Students are fearful of being exposed to or associated with any negative activity while participating in online discussion forums. Safety and rules and regulations concerning participation on the online space were thoroughly discussed, and mentioned before every tutorial commenced. Several challenges and dangers were considered and discussed with both tutees and tutors-dangers such as loss of privacy, bullying, and harmful contacts (Livingston \& Brake, 2010).

\section{Student participation}

The effectiveness of mobile learning can be seen in the shift from what the tutee perceived the role of the tutor to be, to what the tutors were actually doing, and the change in the tutoring methods that followed. Prior to the inclusion of mobile learning, the majority of tutees seemed to be unclear as to what the role of the tutors was. They made several comments on the challenges they experienced with their tutors and the tutorial methods they employed. Tutees mentioned that tutors just stood in the front of the lecture room and explained the work. The online Facebook responses revealed a positive ambiance in tutorials. The incorporation of an online discussion forum created a new space for tutees to participate in (Figure 4).

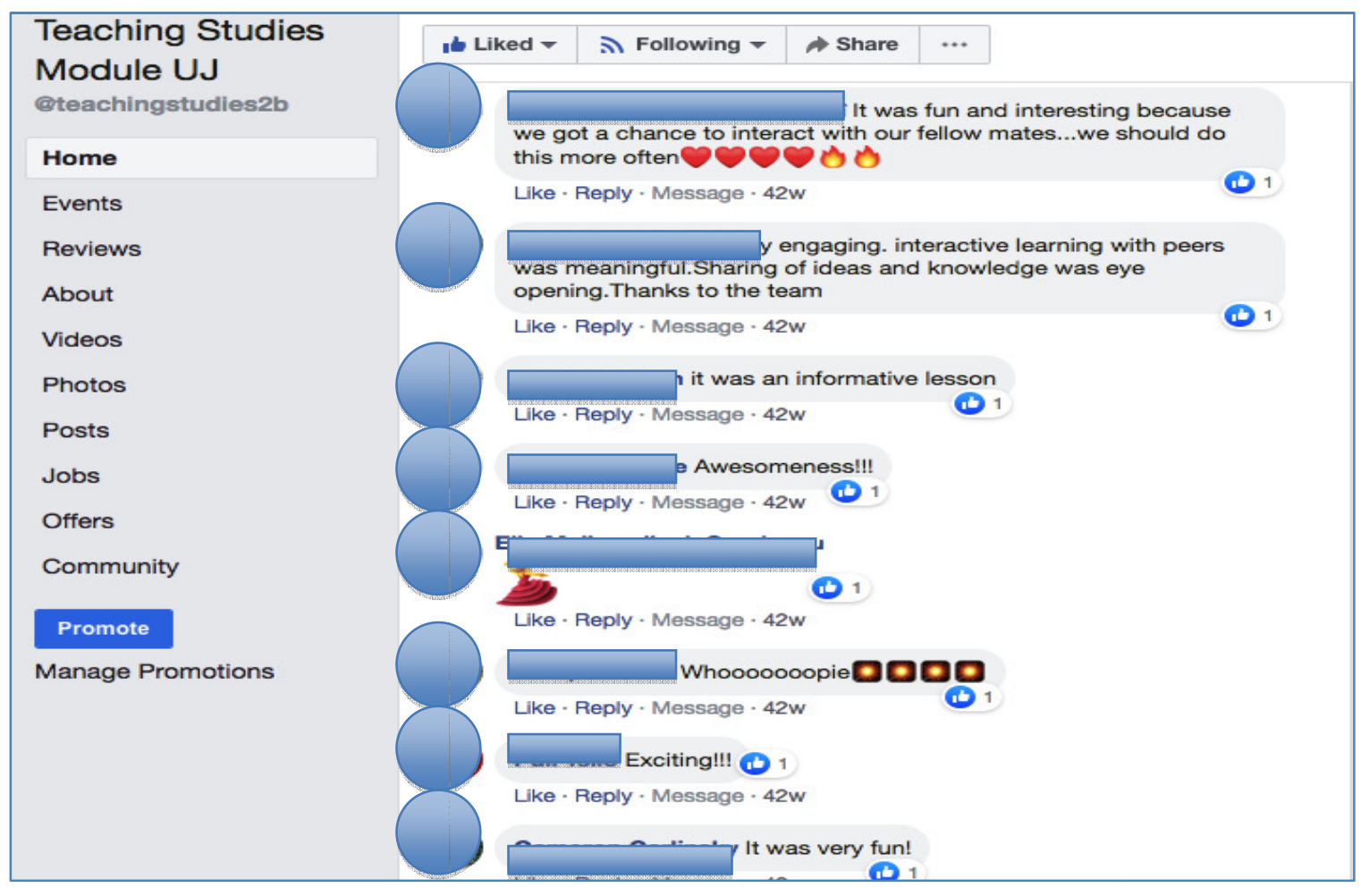

Figure 4: Student participation supported 


\section{More student voices}

Tutee participation increased dramatically and more student voices were heard in the tutorials and online. Tutees further felt that their learning needs were catered for, activities were fun and different, which made the tutorials enjoyable. The continual discussions in and out of the tutorial periods allowed tutees to interact more and give their views at any time. There was no time restriction and tutees were allowed to respond in their own time, even outside of the tutorial time. This meant that tutees absent or late for a tutorial could still be part of discussions and have an idea of what had happened. Figure 5 shows that the topic regarding authentic assessment received 301 comments. The responses included video clips, memes, and comments on the topic.

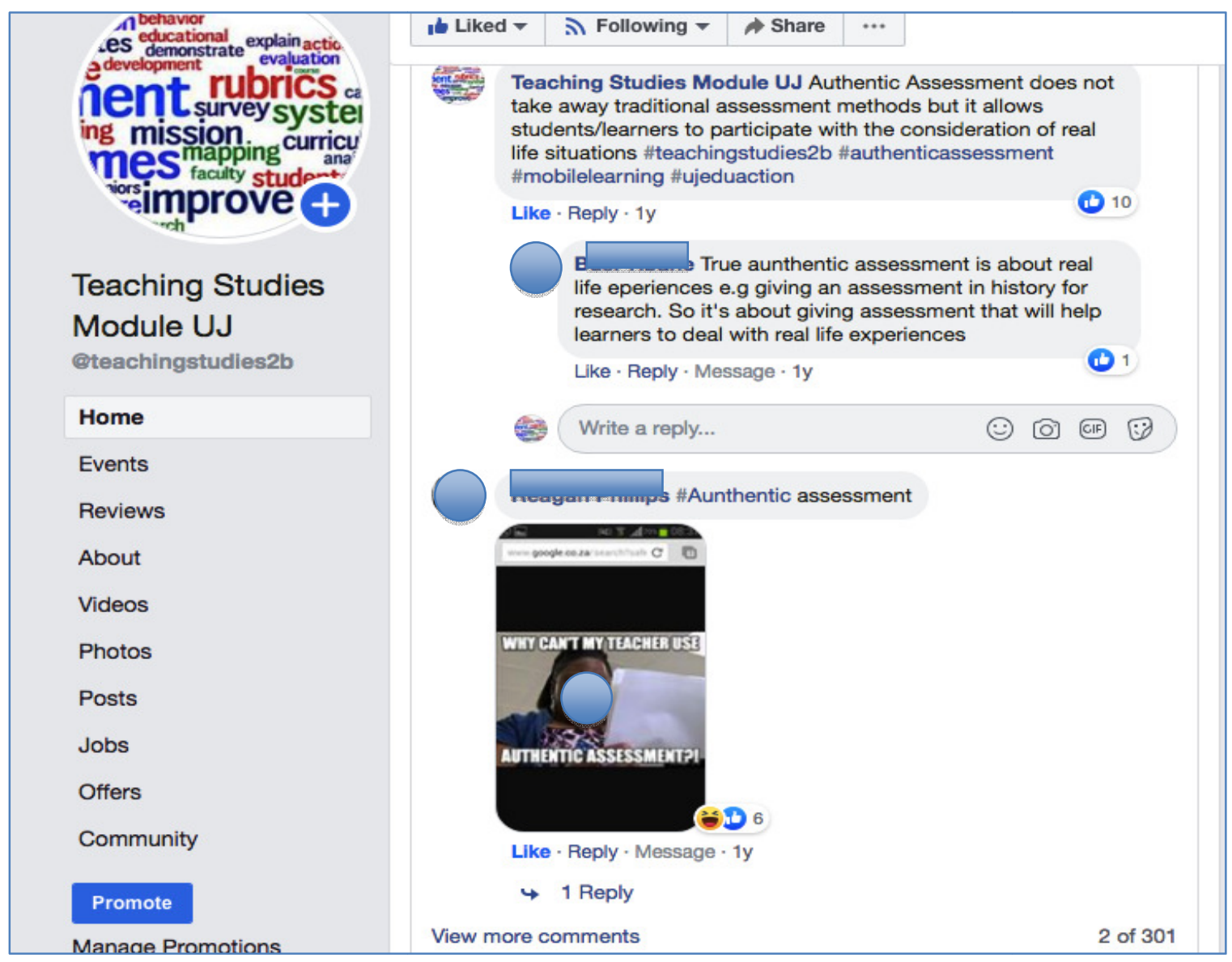

Figure 5: Student voices evident

\section{Authentic learning experience}

The students' learning was deepened and created authentic relations with the content. Outside the lecture venues, conversations, dialogue, and engagement continued to meet tutees' needs. Therefore, mobile learning brings forth a sense of autonomy, agency, empowerment, and authentic learning to tutees that was evident appreciated (see Figure 6). Mobile learning opens minds to the possibility of a radically new paradigm of teaching and learning that encourages us to abandon the constraints of old habituated ways of thinking, learning, communicating, designing, and reacting (El-Hussein \& Cronje, 2010). It opened up new 
learning opportunities built around each tutee and their personal choices of where, when, and how to learn. This cultivated new learning opportunities that are relevant to tutees' day-today activities, and where tutees can learn together and from each other.

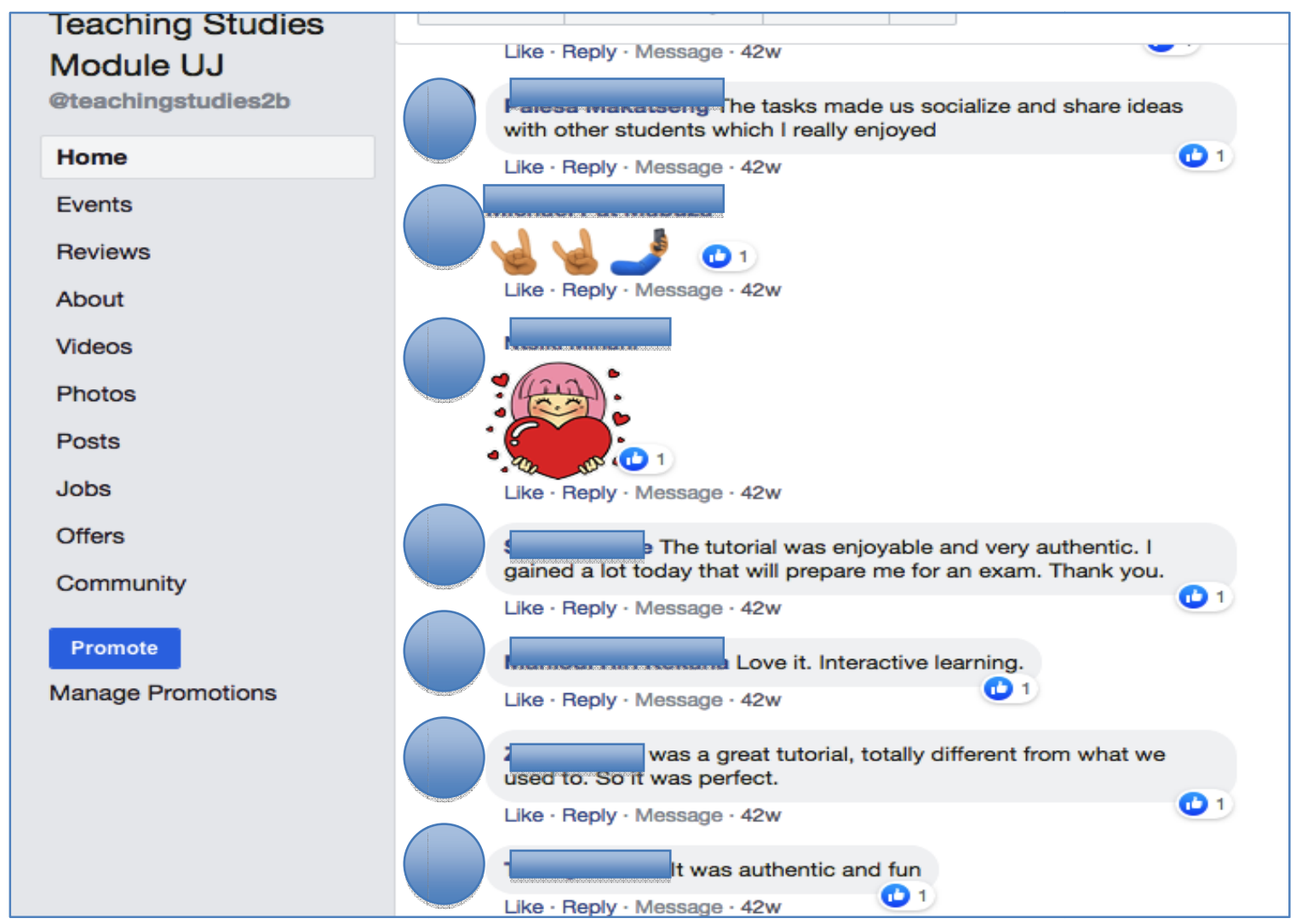

Figure 6: Authenticity is appreciated

\section{Limitations to the study}

Participating tutees and tutors registered for one module gave insightful contributions to this investigation. The research sample is however limited to tutees and tutors of the TST20B2 module who volunteered to participate. We recommend repeating this study in more modules. Furthermore, this study focused on the role of the tutor, therefore, tutors' personality traits should be considered given that they could lead to a difference in the implementation and outcomes of mobile learning. Grading data of the participants could have been considered to show whether tutees did actually learn. Ethical considerations such as cyber bullying could not be dealt with fully and conversations around cyber bullying and online safety were limited. We suggest that in any online participation, serious measures regarding the risks involved should be thoroughly examined not withstanding that UJ has a policy on social media. It is important that students are aware of policies as well as safety and risk concerns involving online participation. 


\section{Conclusion}

A major finding in this study is that tutors have the potential to influence tutees to use their devices for academic use. A blended learning approach where online and face-to-face efforts are implemented in tutorials has proven most effective. The role of the tutor needs to be restructured and repackaged to accommodate technology to meet tutees' learning needs. The results presented in this study reveal a growing interest in mobile learning and in Facebook, in particular. Tutors are mostly employed to assist lecturers to reiterate and clarify concepts, and to assist lecturers with various administrative duties. In this study, we aimed to explore tutors' potential to contribute more during face-to-face tutorials and online environments. It was evident from the data that tutors could positively drive this dynamic method of learning due to peer relations, their own interest, the use of new technologies, and the acceptance of Facebook for mobile learning. The implementation of mobile learning dealt with several challenges that both tutees and tutors faced.

The research questions were: "How do tutors use Facebook to enhance the way in which they tutor?" and "How do tutees experience the implementation of Facebook during tutorials?" The 21st century students displayed an awareness that there should be a change in how tutoring is conducted. Perhaps, with observation and supervision from lecturers and senior tutors and with the inclusion of tutor's ideas, this approach might lead to mobile learning being incorporated in lectures as well. Several tutees nostalgically appreciated traditional tutoring methods, possibly because some did not have mobile devices. These tutees suggested that traditional methods of tutoring should remain. It is our view that a blended learning tutorial approach would be a pedagogically and socially just consideration. Given technological advancements, there is no question that mobile learning is the way forward in tutoring and tutorials. This, however, does not imply a complete jettison of traditional learning approaches, which retain positive aspects.

The successful implementation of mobile learning by using Facebook as a discussion forum requires extensive preparation, training, and planning for tutors. A partnership between what the lecturer lectures and what and how tutors tutor will ensure successful implementation of mobile learning. We propose that mobile devices be incorporated in both the lectures and tutorial spaces. Also, discussion forums should be established in lectures to create a link that continues into tutorials. Including mobile devices requires proper planning for a successful implementation that prioritises content knowledge that is carefully and correctly discussed. Planning can allay fears of security risks that arise from online discussion forums. Security measures need to be emphasised to the tutees, tutors, and lecturers in order to minimise or eliminate possible cyber abuse. A strong online administrative presence from tutors is required to monitor the online space to ensure the safety of tutees. A strong awareness of online safety policies to protect students ought to be part of this project.

The data revealed that tutees and tutors enjoyed collaboration. Mobile devices can be introduced and incorporated in group activities. This has the potential to lead to valuable interactions and collaboration within the structured lecture venue and beyond lecture venues 
and times, however, network technologies are essential in enabling practices and sharing among CoPs (Hoadley, 2012). Collaboration strengthened the CoP formed amongst the students as the activities carried out individually and in groups were solutions to problems in the virtual community based on tutorial rules and community expectations. Mobile learning through collaboration, flexibility, teamwork and authentic learning environments underline CoP.

Facebook has great potential to encourage the use of devices for learning. The tutor, however, remains a crucial component of the process. The support and inclusion of tutors at HEIs is indispensable for the inclusion of technology and mobile devices in lecture venues to succeed. This study shows that tutors remain relevant; if given the opportunity, they can be productive to the benefits of student, lecturers, and the institution. Indeed, tutors' influence reaches to the future of mobile learning and remains relevant to the fourth industrial revolution in which UJ as an institution wishes to participate.

We propose that this paper contributes to both tutoring practices and tutoring policy. We suggest that mobile learning should be considered, and social media platforms be incorporated in tutor practices and the tutoring processes of institutions' tutoring policies. There is a need to implement practical training for the 21 st century students' learning needs and practical training on the implementation of technological advances such as mobile learning. The training should include ethical considerations because of online risks such as cyber bullying. There should be stronger emphasis placed on a zero-tolerance policy and cyber bullying should be a behaviour that is emphasised as being a code-of-conduct violation. This, together with the sanctions, should be outlined explicitly in learning guides and learning management systems online for both the students and staff. There is limited research on tutor processes involving mobile learning in South Africa, therefore, we recommend that more research should be undertaken in this area. Comparative studies with other HEIs in South Africa and Africa may help to determine where HEIs still have to develop and what South Africa's strengths and weakness are compared to other countries in the world.

\section{References}

Alhassan, M. N., Amoah, A. C., \& Anyanful, V. K. (2018). Assessing college of education tutors readiness to integrate hand held devices in teaching and learning of science, mathematics and ICT. Journal of Education and Practice, 9(19), 63-71.

Alsaadat, K. (2009, July). Mobile learning and university teaching. Paper presented at the International Conference on Education and New Learning Technologies, Barcelona, Spain.

Ardichvili, A. (2008). Learning and knowledge sharing in virtual communities of practice: Motivators, barriers, and enablers. Advances in Developing Human Resources, 10, 541-54. 
Barab, S. A., \& Duffy, T. M. (2000). From practice fields to communities of practice. In D. Jonassen \& S. Land (Eds.), Theoretical foundations of learning environments (pp. 2526). Mahwah, NJ: Erlbaum.

Berry, M. J., \& Westfall, A. (2015). Dial D for distraction: The making and breaking of cell phone policies in the college classroom. College Teaching, 63(2), 62-71. doi:10.1080/87567555.2015.1005040

Bloom, B. S. (1984). The 2 sigma problem: The search for method of group instruction as effective as one-to-one tutoring. Educational Researcher, 13(6), 4-16.

Bosch, T. (2009). Using online social networking for teaching and learning: Facebook use at the University of Cape Town. South African Journal for Communication Theory and Research, 35(2), 185-200.

Brooks, J. (2008). Minimalist tutoring: Making the students do all the work. In C. Murphy \& S. Sherwood (Eds.), St. Martin's sourcebook for writing tutors (3rd ed., pp. 168-172). Boston, MA: Bedford St. Martins.

Cheung, W. S., \& Hew, K. F. (2009). A review of research methodologies used in studies on mobile handheld devices in K-12 and higher education settings. Australasian Journal of Educational Technology, 25(2), 153-183.

Coughlan, J., \& Stephen, S. (2011). Student and tutor perceptions of learning and teaching on a first-year skills module in a university computing department. Educational Studies 37(5), 529-539.

Council of Higher Education. (2016). South African higher education reviewed: Two decades of democracy. Pretoria, RSA: Author.

Creswell, J. W. (2012). Educational research: Planning, conducting, and evaluating quantitative and qualitative research (4th ed.). Upper Saddle River, NJ: Pearson Education.

Daraei, S. (2015). A study about effects of Facebook on conceptual learning mathematics. International Journal of Future Computer and Communication, 4(1), 77-81. doi:10.7763/IJFCC.2015.V4.360

Delahunty, J., Verenikina, I., \& Jones, P. (2014). Socio-emotional connections: Identity, belonging and learning in online interactions. A literature review. Technology, Pedagogy and Education, 23(2), 243-265.

Dudezert, A., Heibült, H., \& Boughzala, I. (2006, June). Virtual professional communities and their role for knowledge management. Paper presented at the 11th International Conference of the Association Information and Management (AIM), Luxembourg. Retrieved from 
https://www.researchgate.net/publication/221512207_Virtual_Professional_Communi ties_and_their_role_for_Knowledge_Management

El-Hussein, M. O. M., \& Cronje, J. C. (2010). Defining mobile learning in the higher education landscape. Journal of Educational Technology \& Society, 13(3), 12-21.

Espinosa, L. F. (2015). The use of Facebook for educational purposes in EFL classrooms. Theory and Practice in Language Studies, 5(11), 2206-2211.

Gachago, D., Ivala, E., Backhouse, J., Bosman, J. P., \& Bozalek, V. G. (2013). Towards a shared understanding of emerging technologies: Experiences in a collaborative research project in South Africa. The African Journal of Information Systems, 5(3), 94-105. Retrieved from http://digital commons.kennesaw.edu/ajis/vol5/iss3/4/

Hashim, N. H., \& Jones, M. L. (2007). Activity theory: A framework for qualitative analysis. Retrieved from http://ro.uow.edu.au/commpapers/408

Hassan, S. (2017). Tutors' role in tutorials: "Unpacking" and "repacking" during the semantic journey. South African Journal of Higher Education, 31(3), 99-115.

Hew, K. F. (2011). Students' and teachers' use of Facebook. Computers in Human Behavior, 27(2), 662-676.

Hinds, D., \& Lee, R. M. (2008, January). Social network structure as a critical success condition for virtual communities. Proceedings of the 41st Annual Hawaii International Conference on System Sciences.

Hoadley, C. (2012). What is a community of practice and how can we support it? In D. Jonassen \& S. M. Land (Eds.), Theoretical foundations of learning environments (2nd ed., pp. 287-300). New York, NY: Routledge.

Hrastinski, S. (2008). A study of asynchronous and synchronous e-learning methods discovered that each supports different purposes. EDUCAUSE Quarterly, 31(4). Retrieved from http://www-cdn.educause.edu/library/EQM0848

Ivala, E., \& Gachago, D. (2012). Social media for enhancing student engagement: The use of Facebook and blogs at a University of Technology. South African Journal for Higher Education, 26(1), 152-167.

Jaeger, G. (2016). (Re)examining the socratic method: A lesson in tutoring. Praxis: A Writing Center Journal, 13(2), 14-20.

Khaddage, F., Muller, W., \& Flintoff, K. (2016). Advancing mobile learning in formal and informal settings via mobile app technology: Where to from here, and how? Educational Technology \& Society, 19(3), 16-26. 
Kirschner, P., \& Karpinski, A. (2010). Facebook and academic performance. Computers in Human Behavior, 26(6), 1237-1245.

Klimova, B., \& Poulová, P. (2015). Mobile learning in higher education. Advanced Science Letters 22(5), 1111-1114

Koedinger, K., \& Corbett, A. (2006). Cognitive tutors: Technology bringing learning science to the classroom. In R. K. Sawyer (Ed.), The Cambridge handbook of the learning sciences (pp. 61-78). Cambridge, UK: Cambridge University Press.

Koh, B. J., Kim, Y. G., Butler, B., \& Bock, G. W. (2007). Encouraging participation in virtual communities. Communications of the ACM, 50, 69-73.

Kukulska-Hulme, A. (2010). Mobile learning for quality education and social inclusion (Policy brief. Moscow, Russia: UNESCO Institute for Information Technologies in Education). Retrieved from http://iite.unesco.org/publications/3214679/

Lave, J., \& Wenger, E. (1991). Situated learning: Legitimate peripheral participation. Cambridge, UK: Cambridge University Press.

Livingston, S., \& Brake, D. (2010). On the rapid rise of social networking sites: New findings and policy implications. Children \& Society, 24(1), 75-83. doi:10.1111/j. 10990860.2009.00243.X

Louw, A. (2015). Developing a lecturer workshop for using tablets in the classroom. International Journal of Teaching and Learning in Higher Education, 27(3), 294309.

Mabuan, J., \& Ebron, G. (2017, November). Facebook integration into university classes: Opportunities and challenges. Paper presented at the 31st Pacific Asia Conference on Language, Information and Computation (PACLIC 31), Cebu City, Philippines.

Manca, S., \& Ranieri, M. (2013). Is it a tool suitable for learning? A critical review of the literature on Facebook as a technology-enhanced learning environment. Journal of Computer Assisted Learning, 29(6), 487-504.

Mazman S. G., \& Usluel Y. K. (2010) Modeling educational usage of Facebook. Computers \& Education 55(2), 444-453.

Merriam, S. B. (2009). Qualitative research: A guide to design and implementation. San Francisco, CA: Jossey-Bass.

Miles, M. B., \& Huberman, A. (1994). Qualitative data analysis: An expanded sourcebook. Thousand Oaks, CA: SAGE.

Minor, M. A., Smith, G. S., \& Brashen, H. (2013). Cyberbullying in higher education. Journal of Educational Research and Practice, 3(1), 15-29. 
Mohajan, H. K. (2018). Munich personal RePEc archive: Qualitative research methodology in social sciences and related subjects. Journal of Economic Development, Environment and People, 7(1), 23-48.

MoLeNET. (2010). Mobile learning myths. Retrieved from http://web.archive.org/web/20101015234706/http://www.molenet.org.uk/mobile arinprac/myths

Murillo, E. (2014). Recovering the CoP in "virtual CoPs": A proposed VCoP model. Retrieved from https://www.researchgate.net/publication/323295106_Recovering_the_CoP_in_'virtua 1_CoPs'_-_A_proposed_VCoP_model

Ng'ambi, D., Bozalek, V., Gachago, D., Morkel, J., Ivala, E., Campbell, A., . . Bere, A. (2015). The case studies: Emerging technologies. In V. Bozalek, D. Ng'ambi, D. Wood, J. Herrington, J. Hardman, \& A. Amory (Eds.), Activity theory, authentic learning and emerging technologies (pp. 211-233). New York, NY: Routledge.

Ng'ambi, D., Brown, C., Bozalek, V., Gachago, D., \& Wood, D. (2016). Technology enhanced teaching and learning in South African higher education: A rearview of a 20 year journey. British Journal of Educational Technology, 47(5), 843-858.

Przybylski, A. K., Murayama, K., DeHaan, C. R., \& Gladwell, V. (2013). Motivational, emotional, and behavioral correlates of fear of missing out. Computers in Human Behavior, 29, 1841-1848. Retrieved from https://doi.org/10.1016/j.chb

Robertson, D, N., \& Dasoo, N. (2018, September). Mobile learning and its influence on the tutoring process. Paper presented at the 8th Annual International Conference on Education and e-learning Singapore.

Schwandt, T. A. (2007). The SAGE dictionary of qualitative inquiry (3rd ed.). Los Angeles, CA: SAGE.

Shaw, L., Carey, P., \& Mair, M. (2008). Studying interaction in undergraduate tutorials: Results from a small scale evaluation. Teaching in Higher Education 13(6), 703-714.

Siemens, G. (2005). Connectivism: A learning theory for the digital age. Retrieved from http://www.elearnspace.org/Articles/connectivism.htm

Sundvik, M., Masalin, T., \& Hervonen, H. (2016). Tutors' perceptions of use of tablet computers in PBL sessions. Retrieved from https://www.mededpublish.org/manuscripts/402

Toliver, F. (2011). My students will Facebook me but won't keep up with my online course: The challenges of online instruction. American Communication Journal, 13(1), 59-81. 
Traxler, J. (2007). Defining, discussing, and evaluating mobile learning. International Review of Research in Open and Distance Learning Volume, 8(2), 1-10.

Traxler, J. (2010). Sustaining mobile learning and its institutions. International Journal of Mobile and Blended Learning, 2(4), 58-65.

Truuvert, T. (2014). Enhancing tutorial learning experiences: A programme to develop sessional-tutor teaching skills by raising awareness about learning. Studies in Higher Education 39(1), 20-33.

Underhill, J. (2009). The role of a peer tutor development programme in an academic literacies programme (unpublished master's thesis). University of Johannesburg, South Africa.

Underhill, J., \& McDonald, J. (2010). Collaborative tutor development: Enabling a transformative paradigm in a South African University. Mentoring and Tutoring: Partnership in Learning, 18(2), 91-106.

University of Johannesburg. (2011). University of Johannesburg's strategic drives: 20112020. Retrieved from from www.uj.ac.za/

Veletsianos, G. (2010). A definition of emerging technologies for education. In G. Velestianos (Ed.), Emerging technologies in distance education (pp. 1-22). Edmonton, Canada: Athabasca University Press.

Vygotsky, L. (1978). Mind in Society. Cambridge, MA: Harvard University Press.

Wang, L., \& Ma, Q. (2017). Community of practice: Building a mobile learning community in a higher education institution to promote effective teaching and learning. In S. C. Kong, T. L. Wong, M. Yang, C. F. Chow, \& K. H. Tse (Eds.), Emerging practices in scholarship of learning and teaching in a digital era (pp. 19-38). Singapore: Springer.

Wenger, E. (1998). Communities of practice: The social fabric of a learning organization. New York, NY: Cambridge University Press.

Wenger, E. (2014). Communities of practice: A brief introduction. Retrieved from https://www.researchgate.net/publication/235413087_Communities_of_Practice_A_B rief_Introduction

Woodill, G. (2012). Moving from e-learning to m-learning. Canadian Learning Journal, $16(2), 34-35$

Yin, K. (2009). Case study research design and methods (4th ed.). Thousand Oaks, CA: SAGE. 